\title{
TEXT-BOOKS AND GENERAL TREATISES
}

\author{
BY HERBERT SIDNEY LANGFELD \\ Harvard University
}

Three interesting text-books of psychology have appeared this year. They differ considerably from one another and from the traditional text-book to which we have grown accustomed during the past years.

Hunter's General Psychology (4) is the broadest in scope but the least intensive in treatment of special topics. His plan has been to give the student a general idea of mind in all its manifestations. The originality of the book consists principally in the number of fields described and the arrangement of the material. The behavior viewpoint is prominent but not dominant. Introspective data are given but inasmuch as psychological observation. does not necessarily mean a "looking within" the student is advised to consider introspection as synonymous with observation as practised in the other sciences.

Part I starts with a brief survey of animal psychology with special references to methods of experimentation. There follow descriptions of mental tests and mention of the application of psychology to business, law, etc. The facts of abnormal psychology which are particularly interesting to psychologists, such as paranoia, multiple personality, and psycho-analysis form the next chapter. Part I ends with a brief account of the self and its social aspects, social institutions and racial psychology. This material is presented in the first part of the book in order to interest the student in concrete problems and to counteract the idea that normal human psychology is all-important in the study of the mind. The author states, however, that one may begin with Part II and if it is a short course, the chapters of Part I may be used as collateral read'ng.

Part II begins with Attention, which is described as "the clearness into and out of which objects move." Under the subjective conditions of attention are included instincts, habits and the laws of association. The student is then given an adequate account of the nervous system, and reflex and instinctive action. The chapter on Emotion which includes a description of the important work of Sherrington and Cannon, McDougall's analysis of the emotions and Lipps' theory of empathy precedes the chapter on the Affective 
processes. The psychology of the senses, including Weber's Law and visual space is covered in two chapters. The last chapters are concerned with imagination, memory and thought. Hunter has avoided any lengthy discussions and has been successful in. selecting important facts and presenting them with equal emphasis. In the short space at his command, however, he has been able to do little more than stimulate the student to further study.

The most original text-book which has appeared in years and one which most strongly reflects the opinions and personality of the author is Watson's Psychology from the Standpoint of a $B e$ haviorist (I5). The title is a very honest one. It is an outline of the manner in which one of the behaviorists desires to see psychology developed. Perhaps the term outline may be misleading in that a great many facts of importance are given in some detail. The results are, in many instances, admitted to be tentative and as suggestions for future work. Indeed, there are so many hints for further experimentation and such concrete and practical descriptions of methods which lay entire stress upon objective control that the book will undoubtedly be more useful to research students than to members of an elementary course. As Watson has well described the features which first impress the reader we may quote from his preface; "The present volume does some violence to the traditional classification of psychological topics and to their conventional treatment. For example, the reader will find no discussion of consciousness and no reference to such terms as sensation, perception, attention, will, image and the like. These terms are in good repute, but I have found that I can get along without them both in carrying out investigations and in presenting psychology as a system to my students. I frankly do not know what they mean, nor do I believe that anyone else can use them consistently. I have retained such terms as thinking and memory, but I have carefully redefined them in conformity with behavioristic psychology."

The author has, indeed, been very successful in avoiding these terms, but at times it was necessary to make a considerable circumlocution in order to do so. The "Psychology" is, of course, in terms of stimulus and response. Although no introspection is used the spoken word is admitted as a response of the human organism.

It is impossible to give here more than a few of the outstanding features of the book. It should be said at the outset that most of the 
facts to be found in the traditional text-books are to be found here, but in unexpected settings and original terms. Four methods for obtaining psychological data are described: "I. Observations with and without instrumental control. 2. The conditioned reflex method." 3. The verbal report method. 4. Methods of Testing.

Under the title of "The Receptors and Their Stimuli" are given many of the facts of sensations. Instead of speaking of the sensation of red from wave lengths between 760 and $647 \mathrm{~mm}$., to take an example, we learn that the subject when stimulated by these wave lengths replies "I see red." There are excellent cuts of the sense organs, in fact throughout the book there are numerous well-chosen illustrations of the human anatomy. Space perception and visual hallucination are included in this chapter. Before describing the responses of the organism we are given the essential facts of the nervous system and the muscles and glands. Under the latter are included the liver, kidney, thyroid, etc. The first hereditary motor response to be described is the emotional. Results are given of experiments which the author made upon the reaction of babies to various objects such as pigeons, rabbits, rats, etc. In the first months no fear was shown toward these animals. The reader will find a considerable amount of original data in the investigations by the author, especially upon children, in almost all of the succeeding chapters. As a suggestion for a practical study of the emotions a class experiment is described in which individuals are rated according to various characteristics of their emotional life.

In the chapter upon instincts there is a detailed description of investigations upon nursing, grasping reflex, defense movement, crawling, etc.

Habits are classified as explicit bodily habits and explicit and implicit language habits. We find that it took a hundred and fifty trials for a child to learn through experience to avoid grasping at a flame. The learning curve and retention are treated under the subject of bodily habits. There is a genetic treatment of language which follows a detailed description, with illustrations, of the vocal apparatus. In regard to thought the author states that it may be explicit or implicit.

The material generally found in a chapter on memory is here found in the chapter dealing with language. In the chapter upon "The Organism at Work" Watson states that the psychology of fatigue is in such a helpless position that the concept of fatigue had 
better be dropped. It is simply necessary to state that results are obtained under such and such conditions.

Dr. Arai's experiments upon the work curve are given at some length. A considerable part of the chapter is concerned with the effect of drugs and abnormal conditions upon work. Thepsychology of habit is continued in the chapter on "Personality and its Disturbances." Various methods of studying personality behavioristically are here included. There is very much more on instincts, habits,tand learning in general than is ordinarily found in a text-book, so that even those who desire a fuller and more conventional treatment of sensory psychology may find it an advantage to use this as a supplementary text. The book is written with a great deal of vigor and holds the interest of the reader. It might be added that Watson takes occasion to mention the deficiencies of the air medical service, especially in the employment of unscientific otologists, obstetricians and gynecologists, instead of psychopathologists and psychologists.

Warren's Human Psychology (I4) will appeal to those instructors who have not taken an extreme position in regard to psychological methods, for mind is described structurally, functionally and behavioristically. The aim of the author seems to be to give the student a brief and straightforward account of all the important facts and problems with which a student of experimental psychology should be acquainted before starting independent reading and research. The book therefore covers a very wide range of subjects. As in the case of the other books summarized, there is much originality shown in the classification and arrangement of the material. Another feature of the book is the close coördination throughout the text, of the psychological and the physiological facts. In fact, the nervous mechanism is very strongly emphasized. After a short chapter, descriptive of the organism as a whole, there are several chapters upon the physiology of the nervous system, with special emphasis upon the nervous arc and factors of stimulation and response. The two chapters upon behavior cover reflexes, instincts, and intelligent action. Under the last heading we find a detailed account of the learning process. A short chapter deals with some of the important factors of consciousness. The psychology of the senses is covered in two chapters. Experience is divided into sensation and ideas. There is a general description and comparison of these two elements of consciousness. Perception, imagery, feelings and conations are included under the 
heading "Primary Mental States." We find a general description of perception and special treatment of space, illusion, time, rhythm, discrimination-threshold, etc.

Distinction is made between memory images and images of the imagination. There is also a psychological explanation of general images. Special attention is also given to the various attributes of feeling.

Secondary mental states include the emotions, voluntary action and thought as expressed in language. There is a very elaborate classification of emotions and a list of the sentiments together with their origin. The various types of central control and volition as well as the nature and factors of the will are briefly sketched. The student is informed of the controversy over imageless thought and is given a psychological explanation of meaning and value. A description of the laws of the association of ideas leads to a few pages upon dreams and rational thinking.

A chapter is devoted to a description of the general set of the organism, producing attitudes which are termed interest, desire, attention, etc. After showing what is meant by character and classifying the temperaments, the author shows how these various phases make up the general character or self. There is a useful summary of the contents of the book and several pages of special conclusion. Four problems are discussed in the appendix, namely the mind and body relation, including the question of thought transference, mechanism and purpose, neural activity and theories of color vision. At the end of each chapter there are references to chapters of standard text-books which may be used as collateral reading. There are also several practical exercises, directions for performing which are given at the end of the book. There are excellent illustrations, especially of the essentials of the human anatomy. (The recent text-books in psychology make it unnecessary to use a separate physiology in general courses.) The book seems best suited for advanced courses. It should be used in elementary courses only if the students are above sophomore grade.

Pillsbury has made a number of important changes in a new edition of his Essentials of Psychology (ro). The various topics have been brought up to date, wherever it has been deemed necessary. The greatest number of changes have been made in the chapters on "Memory and Imagination" and on "The Emotions," ten pages having been added to the former. In the latter chapter the latest facts, such as the results of Cannon's work, are now in- 
cluded. A new chapter entitled "The Types of Mind" which deals briefly with the nature and method of intelligence tests, has been added. Many of the paragraph headings have been altered and new ones added. There are several new cuts. The exercises and references at the end of each chapter have been thoroughly revised and there is now in addition a list of questions. The author has also improved his style throughout the book.

Fröbes (2) considers that his text-book is a supplement to a general outline and to research in special fields. He states that his book differs from the general run of text-books in that it is midway between a condensed outline and a reference book intended for specialists. His aim has been to give to psychologists a book somewhat similar to that which medical men have in Tigerstedt's Physiologie.

The book is ponderous both in size and style. Only the first volume has as yet appeared and its six hundred odd pages brings one only to the end of the chapter on the laws of association.

One might describe the book as a composite photograph of the writings of the better-known psychologists such as Wundt, Müller, Stumpf, Fechner, Titchener, Witasek, etc. Very few references are beyond $19 \mathrm{r}_{4}$ and many of them date from the early days of experimental psychology. The treatment is very conservative and there is absence of any definite point of view or critical analysis. The modern tendencies in experimental psychology have not been recognized and few references have been made to the work done in America. There is no attempt at originality, the various subjects being explained with quotations or paraphrases from various authors. For example, under the differential threshold for pitch one is given results from Preyer, Witasek, Brentano and Stumpf within the space of ten lines.

The first third of the book deals with the sensations. The second third with auditory perception and space, and movement. In the last third of the book there is a brief treatment of thought, perception and comparion. Following this there is a relatively extensive description of psychological methods including the principles of correlation, and finally a statement of the laws of association. The book is a presentation of experimental results rather than methods or theories. It may be helpful to the student in starting a problem or writing a seminar paper, especially if he has not a complete bibliography or good library facilities.

Kaploun's Psychologie generale (5) is a system of psychology 
which, as the sub-title suggests, is based upon a study of dreams. The author's desire is to be empirical. He has therefore developed a system of psychology from about five hundred observations upon himself which he has made during the course of five years $\mathrm{He}$ has refrained from using the observation of others on account of their unreliability. One suspects that the author's generalizations are, to some extent, determined by his training in the philosophical psychology of the last century. One is reminded, in places, of Lipps, although he has not even Lipps' tolerance for modern experimental facts. It is impossible, in this place, to review the book in detail. An idea of it may be obtained from the fact that the author presupposes three egos. There is the central ego which is "adynamique." It uses no energy except, perhaps, the vital energy which only disappears at death. There is also the automatic ego and a third ego which is a combination of the two. Much use is made of the concept of the focus of the mind, which is not to be confused with attention, and the explicit function which probably corresponds to Wundt's apperceptive mass.

Goddard's Psychology of the Normal and Subnormal (3) is not only for students in normal schools and colleges, but also for parents and for the general reader who is interested in teaching, in social problems, vocational guidance, etc. The various subjects are treated under the threefold aspect of physiology, normal, and abnormal psychology. Extensive descriptions are given of the neural basis for the various forms of mental activity. These activities are then described as they appear in the normal individual. Thus far the book resembles the usual text-book. The reader, however, is led beyond this into the normal field. In fact the impression one receives is that of an abnormal rather than normal psychology. The facts of the two fields, however, are brought closely together so that they supplement each other. There are numerous illustrations and a summary is given at the end of each chapter.

The first chapters are concerned chiefly with the nervous system and its development. Memory and attention and the association of ideas, are shown to be inherent properties of the nervous mechanism. The higher mental processes are then described. Considerable attention is given to the problems of emotional life, and to will, action and habit. The author has presented a view of emotions which he believes has not before appeared in a textbook. In the appendix he has printed Mosso's article on 
"The Mechanism of the Emotions." A short second part of the book describes some of the possibilities of applying the principles of the first part to practical problems of life especially to the training of the feeble-minded. The book is written in simple, and so far as possible, non-technical language. The facts are frequently illustrated by experiences which will be readily understood by the general reader. As a textbook it is probably best adapted to a course in abnormal or in comparative psychology.

Bridges in An Outline of Abnormal Psychology ( $\mathrm{I}$ ) lists and classifies the abnormal manifestations of the various fields of psychology. $\mathrm{He}$ also describes very briefly the theories and explanations of these manifestations. Part I follows the division of the ordinary human textbook, namely sensation, perception, memory, etc. Part II lists the symptom complexes of insanity and Part III those of the border-line diseases. There are lists of references at the end of each chapter. The author desires the book "to serve as a guide for students of abnormal psychology in the absence of a comprehensive text-book." It seems to the reviewer that the book will be useful to students of abnormal psychology, even though they may have access to text-books on the subject, for it will be of considerable aid to them in systematizing and remembering the many necessary facts of the subject. ${ }^{1}$

Starch's Educational Psychology (13) may be used as a text-book, as well as a reference book for those working in the field of educational psychology. The author's chief aim has been to present the most important experimental data in the field of education. $\mathrm{He}$ has not dealt to any extent with theory, since he desires his book to be as practical as possible. He has also devoted less space to a discussion of instincts, fatigue and imagery than has usually been done. The first part of the book is concerned with the native equipment of the human organism. The range of variation in the capacities of pupils is shown. There is also a treatment of the correlation of various capacities. This leads to a discussion of results relative to sex differences. In the part upon the inheritance of mental traits there is first a description of the work upon defectives and then of the resemblance of brothers and sisters and twins. This part ends with a description of intelligence tests.

Part II gives considerable data upon the learning curve and the transfer of training. The third part is concerned with the

'A critical review of this book by S. I. Franz appeared in the Bulletin, June, 1919. 
methods of measuring the ability in learning special school subjects. The author considers this part unique for a text-book. Considerable data are presented which will assist in teaching these subjects. A large part of the book consists of tables and graphs.

Lipmann's Psychologie für Lehrer (6) is similar in treatment to his psychology for lawyers. It is interesting in style and subject matter. He has been able, in a short space, to present some of the most essential facts clearly and concisely. It is especially interesting to note the change which has taken place regarding the German ideas on educational methods. When on the subject of "Authority" Lipmann states that the teacher should make very little use of his authority in his relation to the pupil. He should not insist upon his statements being accepted uncritically, but should prove, so far as possible, the assertions he makes. Further the student should be told that true religious values and ideals are a matter of faith rather than knowledge and should be distinguished from socalled dogmas which masquerade under the guise of religion. Attention is particularly directed to the reliability of statements made by children, to memory, fantasy, and play, feeling, will and character, including questions of morality. There is no attempt to treat these subjects more than superficially, but the book will undoubtedly prove suggestive to teachers, especially in Germany.

Although Link's Employment Psychology (7) is essentially for those who desire to enter the field of industrial psychology, and for the business man who wishes to know the practical value of psychology in the selection of employees and in putting the right man in the right place, the book will make a good text for part of a course in applied psychology. Link is very conservative in his estimate of the value of the various psychological tests he describes. The book will probably win the confidence of the business man. It should also put the student in the proper attitude toward applied work. The reader is shown how the tests are devised, how their practicability is determined, and finally the manner in which they are applied, the results obtained, the calculations made and the deductions drawn. Many actual experiments in selecting the personnel for different businesses are described in detail. Not only are successful methods given but also some which were negative in result. By this means the student is warned of the danger of too much optimism and advised of the necessity for great patience. A number of tests for the selection of employees are briefly described. Part of the book is devoted to trade tests. Another part deals 
with the method of comparing men according to impression, output, etc. The last part of the book contains general remarks upon employment methods. An appendix gives a more detailed account of some of the tests and methods of computing results. The book, though serious in tone, has an easy interesting style.

Seashore believes that it is possible, through scientifically determined tests, to decide whether one possesses sufficient musical ability to warrant fitting oneself for a musical career. In his book, The Psychology of Musical Talent (12), he has described tests for determining the presence of the essential features in musical ability, such as the sense of pitch, of intensity, of timbre, of consonance, etc. Experiments which have been carried on in Seashore's laboratory are described. There are also illustrations and descriptions of instruments invented by the author. There are included short explanations of the concepts necessary to an understanding of the psychology of music. The book will be of value to teachers of music, and instructors will find it useful in courses of general and applied psychology.

Peterson and David's The Psychology of Handling Men in the Army (9) will be of value not only to officers but to students of military psychology and may also serve as collateral reading for a course in applied psychology. The subjects treated are competition, play, team-play, leadership, the principles of learning, habit, discipline, and loyalty. Most of the chapters are divided into three parts. The first part is written by Lieut. David in a somewhat popular style, setting forth the practical aspects of the subject. Peterson explains the underlying psychological principles in the second part. The third part shows the immediate application of the facts and also contains quotations relative to the subject from competent army officers.

Part I of Marshall's Mind and Conduct (8) is entitled "The Correlation of Mind and Conduct." The first question discussed is the nature and limits of the correspondence of consciousness and behavior and the place of the subconscious. In behavior we find instinctive action opposed to adaptive action. In consciousness there is the opposition of instinctive feelings and reason. Habits are termed pseudo-instincts. If instinctive action is slowed down it shows the characteristics of adaptive action. On the conscious side, as action becomes more automatic instinctive feelings take the place of thought, and then, in turn disappear. The action thus becomes entirely unconscious. 
Marshall describes the empirical self which is a "similacrum of the non-presentable self" or conceptual self which is described as an "undifferentiated mass of psychic elements." It is from the ego of self-consciousness that we learn the general nature of the self.

The second part deals with "Some Implications of the Correlation." The chief characteristic of self is the creativeness, evidence for which is to be found in the existence of ideals which are not part of the real world. In discussing freedom and responsibility the author states that we never do anything which, at the time of action, seems to us irrational. We are responsible for our acts in that we are the author of them. In this sense responsibility has ethical significance.

In the third part Marshall discusses the rôle of pleasure, happiness, intuition and reason in conduct.

Ritter in his two volumes upon The Unity of the Organism (II) has given much information upon the structure of the cells, cell theories, the relation of the organism to the cells, neural integration and nerve action. He discusses the connection between the physical and psychical and closes with a theory of consciousness. His specific information is drawn from the works of others. As he himself states in the preface, he is a complete stranger in the fields treated, namely the chemistry of the organism, heredity, human consciousness and the nature of knowledge. The book is highly speculative and philosophical. Owing to lack of definition in the style, it makes rather difficult reading.

\section{REFERENCES}

1. BRIDges, J. W. An Outline of Abnormal Psychology. Columbus: R. G. Adams \& Co., 1919. Pp. 126.

2. FröвEs, J. Lehrbuch der Experimentellen Psychologie. Frieburg, i/Br.: Herdersche Verlagshandlung, 1917. Pp. xxvi +605.

3. Goddard, H. H. Psychology of the Normal and Subnormal. New York: Dodd, Mead, 1919. Pp. svii + 349 .

4. Hunter, W. S. General Psychology. Chicago: University of Chicago Press, 1919. Pp. xiii +35 I.

5. Kaploun, A. Psychologie Generale. Lausanne: Librairie Payot \& Cie., 1919. Pp. 205.

6. LipMann, O. Psychologie fur Lehrer. Leipzig: Barth, 1920. Pp. vi + I96.

7. Link, H. C. Employment Psychology. New York: Macmillan, 1919. Pp. $\mathrm{xii}+440$.

8. Marshall, H. R. Mind and Conduct. New York: Scribner, 1919. Pp. viii +236.

9. Petrerson, J., \& David, Q. J. The Psychology of Handling Men in the Army. Minneapolis: Perrine Book Co., I919. Pp. iii +146. 
Io. Pillsbury, W. B. Essentials of Psychology. (Revised Edition.) New York: Macmillan, 1920. Pp. xiii +428 .

11. Ritter, W. E. The Unity of the Organism. Boston: Richard Badger, 1919. 2 vols. Pp. xxix $+398 ; x v+408$.

12. Seashore, C. E. The Psychology of Musical Talent. Boston: Silver, Burdett, 1919. Pp. xvi +288.

13. Starch, D. Educational Psychology. New York: Macmillan, 1919. Pp. viii +473 .

14. Warren, H. C. Human Psychology. Boston: Houghton, Mifflin, 1919. Pp. $\mathrm{xx}+460$.

15. Watson, J. B. Psychology from the Standpoint of a Behaviorist. Philadelphia: Lippincott, 1919. Pp. xi +429. 